\title{
Iliotibial band release as an adjunct to the surgical management of patellar stress fracture in the athlete: a case report and review of the literature
}

\author{
Anthony Keeley*1, Paul Bloomfield ${ }^{2}$, Peter Cairns ${ }^{1}$ and Robert Molnar ${ }^{1}$
}

\author{
Address: ${ }^{1}$ Sydney Orthopaedic Trauma and Reconstructive Surgery, Sydney, Australia and ${ }^{2}$ Narrabeen Sports Medicine Centre, Sydney Academy of \\ Sport, Sydney, Australia \\ Email: Anthony Keeley* - toreyandtony@ hotmail.com; Paul Bloomfield - paulcaz@optusnet.com.au; \\ Peter Cairns - pcairns@orthotrauma.com.au; Robert Molnar -rmolnar@optusnet.com.au \\ * Corresponding author
}

Published: 30 July 2009

Sports Medicine, Arthroscopy, Rehabilitation, Therapy \& Technology 2009, I:15 doi:10.1 186/1758-2555-I-

15

This article is available from: http://www.smarttjournal.com/content/l/I//5

(c) 2009 Keeley et al; licensee BioMed Central Ltd.

This is an Open Access article distributed under the terms of the Creative Commons Attribution License (http://creativecommons.org/licenses/by/2.0), which permits unrestricted use, distribution, and reproduction in any medium, provided the original work is properly cited.
Received: 18 April 2009

Accepted: 30 July 2009

\begin{abstract}
Stress fracture of the patella is rare. In this report, a case of patellar stress fracture occurring in an amateur athlete is presented, and an operative adjunct to the surgical management of this condition is proposed.

A review of the English literature identified 21 previous cases of stress fracture of the patella, the majority in young athletes. None of these reports discussed treatment addressing the pathological process contributing to patellar stress fracture.

The subject of this case report is a young male netballer who presented with a transverse stress fracture in the inferior third of his patella, on a background of patellofemoral overload. The patient underwent open reduction and internal fixation of his patella, combined with release of the iliotibial band. He returned to training after 6 weeks.

The previous literature suggests that operative fixation is indicated for the treatment of displaced patellar stress fractures. Iliotibial band release, as a surgical adjunct to this treatment, may address the pathology of these fractures, and facilitate a return to sport at the highest level.
\end{abstract}

\section{Background}

Stress fracture of the patella is rare, with only 21 cases previously reported in the English literature.[1-13] Patellofemoral contact stress, combined with tension from the extensor mechanism, leads to increased tensile stress on the anterior surface of the patella with subsequent microfracture and propagation. Undisplaced fractures are usually managed non-operatively, while displaced fractures are best treated operatively. In most cases patients report a return to sport at close to premorbid levels usually between 3 and 6 months. No previous reports discuss treatment addressing the pathological process contributing to patellar stress fracture.

We report a case of displaced transverse stress fracture of the patella in an amateur athlete. In addition to operative fixation of the fracture, the patient also underwent surgical release of his iliotibial band (ITB). This procedure 
attempts to decrease patellofemoral stress and may facilitate an earlier return to activity.

\section{Case presentation}

A 20 year old male presented with sudden pain in the anterior aspect of his left knee, accompanied by a loud cracking sound. The injury was sustained whilst jumping during a game of basketball. He was unable to continue playing, and weight bearing became difficult as swelling progressed. Preceding this injury, he had been diagnosed with patellofemoral pain syndrome on the basis of a 3 month history of anterior knee pain. There was no history of prior trauma or surgery to the knee. He played representative indoor netball, social basketball, squash and he trained 6 days per week. His left leg was his pivoting leg for netball.

Examination at the time of presentation revealed a moderate effusion, swelling and tenderness over the inferior half of the patella, and a decreased range of motion. Straight leg raise (SLR) was painful, but intact. The patient had a tight ITB, as assessed by the Iliotibial Band/Lateral Retinaculum test.[14]

Radiographic examination revealed a transverse fracture at the junction of the mid and distal thirds of the left patella (Fig 1). MRI scan confirmed the fracture and also revealed sclerosis at the margins of the fracture site (Fig 2).

The patient underwent operative treatment of the patella fracture (Fig 3). An anterior longitudinal incision was made over the patella, the fracture was exposed, and the sclerotic fracture margins were debrided. The fracture was then reduced and compression applied with a clamp. Fixation was achieved with a Synthes fully threaded $3.5 \mathrm{~mm}$ cortical screw. Examination under anaesthesia confirmed a tight ITB and this was subsequently released. A $2 \mathrm{~cm}$ transverse incision was made at the level of the superior pole of the patella, and the ITB was completely divided transversely at this level. Subsequent examination using the ITB/Lateral Retinaculum test demonstrated decreased ITB tension.

Post-operatively, the patient was allowed to weight bear as tolerated, and a Zimmer knee splint was worn for the first 2 weeks. Rehabilitation was then commenced as per the McConnell knee program,[15] modified to allow return to sport at 6 weeks. Range of motion exercises were commenced at 2 weeks post-operatively when uncomplicated wound healing was documented. Muscle strengthening and proprioception training commenced at 4 weeks. At 6 weeks he returned to unrestricted training, and 3 weeks later to unrestricted sport. The patient was able to return to his premorbid level of sport. His Lysholm knee scores were: 25 post-injury; 37 immediately post-operatively; 93 at 6 weeks; and 94 at 12 months post-operatively.

\section{Discussion}

The first report of patellar stress fracture was in 1943 by Muller, [16] and then in the English literature by Devas, in 1960.[3] Stress fractures of the patella have since been reported in athletes, military recruits, patients with knee flexion contractures secondary to cerebral palsy,[17-19] and post-operatively following patellar surgery.[20] They account for less than $1 \%$ of all stress fractures. There have been 21 case reports of patellar stress fracture in athletes in the English literature since 1960 (Table 1).[1-13]

Stress fractures are defined as a partial or complete fracture of bone due to an inability to withstand a non-violent stress that is applied in a rhythmic, repetitive, sub-threshold manner.[21] They may be subdivided into two types: fatigue and insufficiency. Fatigue fractures occur in bone subjected to submaximal stress loads, such as in athletes or patients with cerebral palsy.[6,22-24] Insufficiency

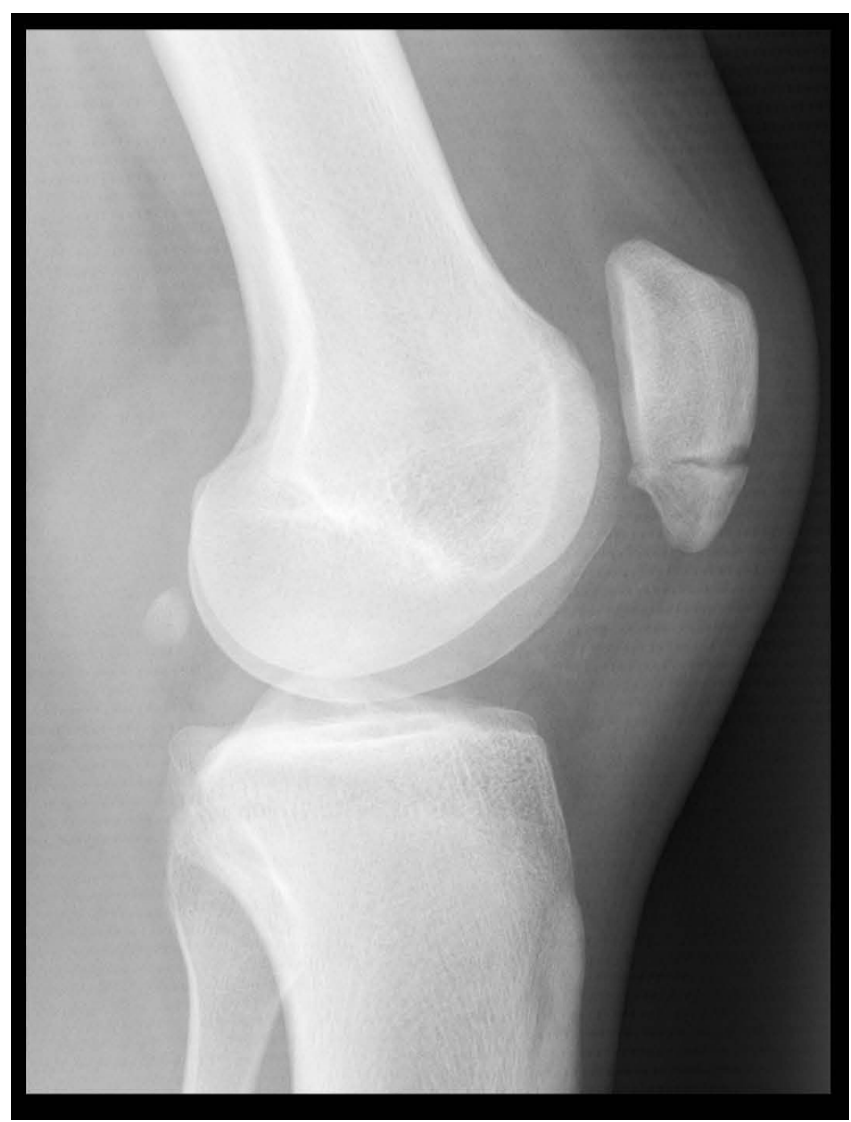

Figure I

Lateral radiograph of patient's knee showing minimally displaced transverse fracture of inferior third patella. 


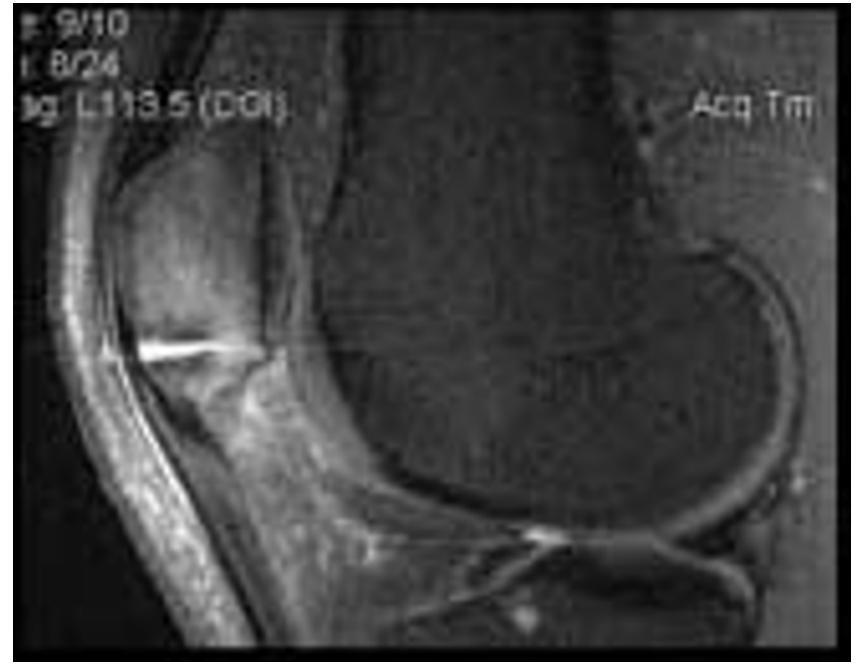

Figure 2

Sagittal plane T2 MRI showing fracture, surrounding bony oedema, and sclerosis of fracture margins.

fractures occur in previously weakened bone under physiologic stress, such as post patellar resurfacing arthroplasty or cruciate ligament reconstruction using patellar tendon.[20]

To explain the aetiology of stress fractures, two theories have been proposed: muscle fatigue, and direct muscle action. Muscle fatigue reduces its ability to absorb shock, thus allowing greater force transmission to bone, which increases local stress.[25] Conversely, muscle contraction itself creates a repetitive stress at a localised site within the bone.[26] Patellar stress fractures probably result from a combination of these mechanisms.

The classic presentation of patellar stress fracture is a young athlete with acute onset of severe anterior knee pain, often associated with a crack or pop, and inability to continue sport.[1-13] The patient has a high intensity, high frequency training program, often involving running or jumping. There is a history of gradual onset of peripatellar pain of weeks to years duration prior to the acute injury. There is usually no history of previous injury to the knee. There is localised swelling and tenderness over the inferior half of the patella, occasionally a small effusion or mildly decreased range of movement (ROM), and often a decreased ability to weight bear or straight leg raise.

The acute episode corresponds to progression from localised microfractures to complete fracture. Early diagnosis therefore minimises the need for surgery. The fracture may occur in either a transverse or vertical direction. Radiographs are sensitive initially in only one third of cases, and later in only half.[27] A skyline view is essential. MRI or

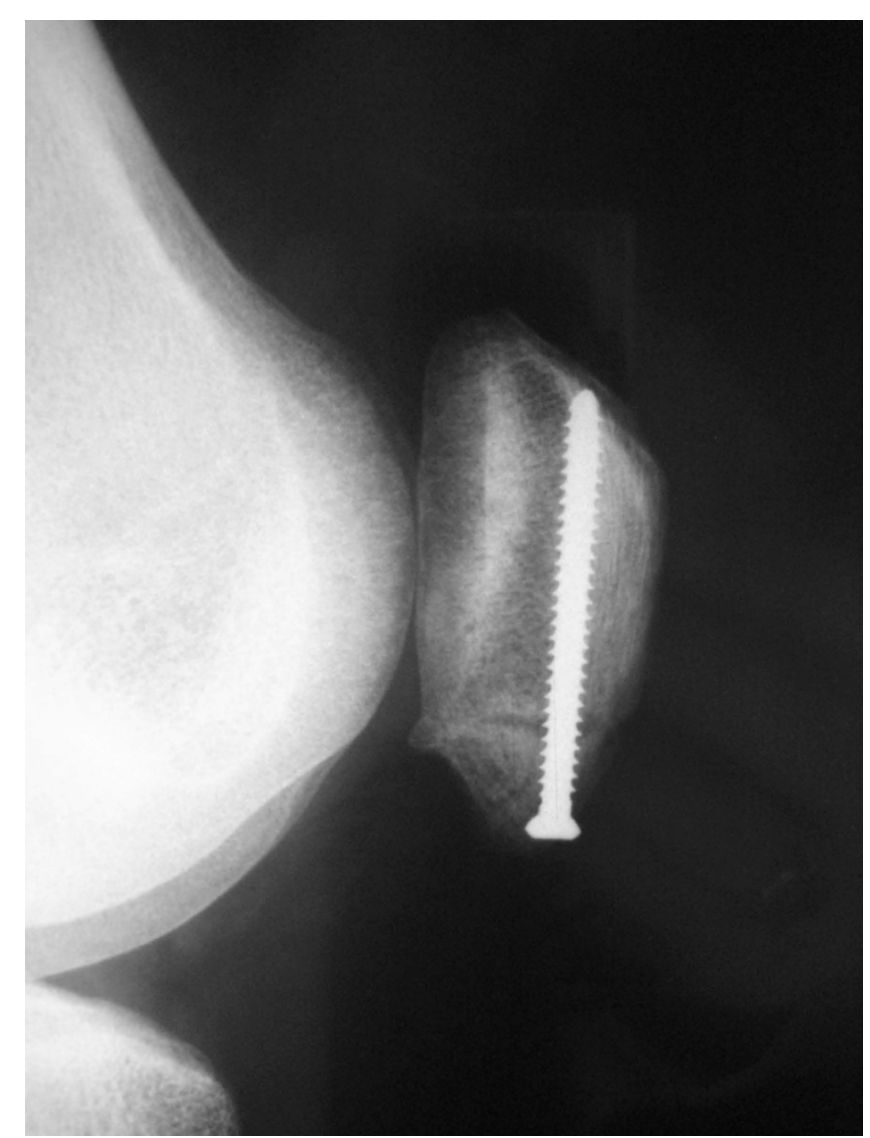

Figure 3

Post-operative lateral radiograph of patella showing reduction and screw fixation of transverse patella fracture.

bone scan will be positive early and should be used in cases where radiographs are normal.

Anatomically, there are numerous tendinous and ligamentous attachments to the patella, which act as static and dynamic stabilisers. The attachments of the extensor mechanism are important biomechanically and pathologically. The thin distal patella is enveloped by the patellar tendon over its distal third, while the thicker proximal patella is covered anteriorly by the superficial layer of the quadriceps tendon over its proximal two thirds.[5] In addition to the quadriceps and patellar tendons, lateral structures play an important role in the aetiology of patellar stress fractures. The lateral retinaculum attaches to the patella on its lateral side, and is the main lateral stabiliser. The ITB divides into the iliopatellar band (IPB) and the iliotibial tract (ITT) at the level of the knee joint.[28,29] Through these two structures, the ITB has many distal attachments, including the distal femur, lateral intermuscular septum, and Gerdy's tubercle, via the ITT; and the lateral aspect of patella and patellar tendon, via the 
Table I: Characteristics of previously reported cases

\begin{tabular}{|c|c|c|c|c|c|c|c|c|}
\hline Author & Age & Sex & Sport & Type* & Location & Displaced & Treatment $^{\wedge}$ & Outcome \\
\hline \multirow[t]{2}{*}{ Devas[3] } & 23 & $M$ & Running & $\mathrm{V}$ & Lateral & Yes & $\begin{array}{l}\downarrow \text { activity, excision at } 3 \\
\text { months }\end{array}$ & Full return to running \\
\hline & 28 & $M$ & Running/hockey & $\mathrm{T}$ & Mid I/3 & No then Yes & ORIF (sutures) & Full sports \\
\hline Dickason[4] & 12 & $M$ & Soccer/basketball & $\mathrm{T}$ & Distal I/3 & No & Cast & Full function \\
\hline \multirow[t]{3}{*}{ Iwaya[7] } & 12 & M & Sprinting & v & Lateral & Min & $\downarrow$ activity & Sport 5 months \\
\hline & 11 & $M$ & Fencing & v & Lateral & No & $\downarrow$ activity & Sport 2 months \\
\hline & 10 & $\mathrm{~F}$ & Gymnastics & $\mathrm{V}$ & Lateral & No & $\downarrow$ activity & Sport 3 months \\
\hline Schranz[12] & 27 & $M$ & Running & V & Lateral & Min & Excision & Not reported \\
\hline Jerosch[8] & 20 & $M$ & Soccer & $\mathrm{T}$ & Distal I/3 & Yes & ORIF (TBW) & Normal 2 yrs \\
\hline Rockett[II] & 20 & $M$ & Basketball & $\mathrm{T}$ & Distal I/3 & No & Not reported & Not reported \\
\hline \multirow[t]{2}{*}{ Teitz[13] } & 23 & $M$ & Skiing/sailboarding & $\mathrm{T}$ & Distal I/3 & Min & ORIF (TBW) & Near normal 18 months \\
\hline & 36 & $\mathrm{~F}$ & Belly dancing & $\mathrm{T}$ & Distal I/3 & No & Cast & Good function 6 months \\
\hline Pietu[10] & 16 & $M$ & Skiing/basketball & $\mathrm{T}$ & Distal I/3 & Min & Splint & Sport I yr \\
\hline Garcia Mata[6] & 23 & $M$ & Soccer & $\mathrm{T}$ & Distal I/3 & Min & Splint/Cast & Sport 3 months \\
\hline \multirow[t]{5}{*}{ Orava[9] } & 25 & $M$ & Volleyball & $\mathrm{T}$ & Distal I/3 & Min & Cast & Sport 6 months \\
\hline & 19 & $\mathrm{~F}$ & Running & v & Lateral & Min & $\begin{array}{l}\downarrow \text { activity, excision at } 5 \\
\text { months }\end{array}$ & $\begin{array}{l}\text { Training } 2 \text { months post } \\
\text { excision }\end{array}$ \\
\hline & 19 & $\mathrm{~F}$ & High jump & $\mathrm{T}$ & Distal I/3 & No & ORIF (TBW) & Sport 6 months \\
\hline & 22 & $M$ & Soccer & $\mathrm{T}$ & Mid I/3 & Min & Cast, ORIF, bone graft & Sports 3 yrs $(\downarrow$ level $)$ \\
\hline & 21 & $\mathrm{~F}$ & Orienteering & $\mathrm{T}$ & Distal I/3 & Yes & ORIF (TBW) & Sport 6 months \\
\hline Brogle $[I]$ & 22 & $M$ & Basketball & $\mathrm{T}$ & Distal I/3 & Min & ORIF (screw + TBW) & Sport 10 months \\
\hline Garcia Mata[5] & 12 & $M$ & Soccer & $\mathrm{T}$ & Distal I/3 & Min & ORIF (screw) & Training 6 weeks \\
\hline Crowther[2] & 35 & $M$ & Tennis & $\mathrm{T}$ & Distal I/3 & No then Yes & ORIF (TBW) & Normal 10 months \\
\hline
\end{tabular}

$* \mathrm{~V}=$ Vertical; $\mathrm{T}=$ Transverse

$\wedge$ ORIF = Open reduction internal fixation; TBW $=$ Tension band wiring

IPB. $[28,29]$ Both the superficial oblique and deep transverse layers of the lateral retinaculum arise mostly from the IPB.

When the knee is flexed, contraction of the quadriceps compresses the patella against the femoral condyles and trochlea. This patellofemoral compression force increases with the magnitude of quadriceps contraction and the degree of knee flexion. In 30 degrees of flexion, the quadriceps force required to maintain stance is equal to 2.1 times body weight.[30] In deep knee flexion, the patellofemoral joint reaction force is around 6-7 times body weight.[31,32]

In the flexed knee, bending stress is applied to the patella, with the anterior surface subjected to tensile forces, and 
the subchondral zone under compression. Finite element analysis and microradiographic studies have demonstrated that the trabecular orientation in the patella corresponds to the principal stress directions, $[33,34]$ and that trabecular density corresponds to the magnitude of the stress.[35] Previous authors have suggested that these forces are directly responsible for the propagation of patellar stress fractures.[1,13] Transverse patellar stress fractures typically occur at the junction of the middle and distal thirds. The anatomic arrangement of the attachments of the patellar and quadriceps tendons causes a local concentration of stress, which predisposes to the development of stress fractures at this junction.

Beyond 30 degrees knee flexion, the patella engages the trochlea, and the ITB and IPB pass posterior to the lateral femoral condyle. The ITB thus exerts a posterolateral force on the patella in this range. Therefore, if the ITB is tight, the patellofemoral joint reaction force is increased.[36] This concept is supported by many biomechanical and clinical studies in the literature. Several authors have suggested that ITB tightness is a contributing factor for patellofemoral pain syndrome (PFPS),[14,15,37-41] and lateral patellar maltracking. [38,42-46] Others have suggested ITB stretching as a treatment for patellofemoral dysfunction.[42,47-49] Lateral retinacular tightness is well recognised in patients with various forms of patellofemoral dysfunction.[36,48,50-56] Puniello found a significant association between medial patellar glide and ITB flexibility in patients with PFPS.[38] He theorised that the anatomic arrangement of the ITB and lateral retinaculum provides a mechanism whereby vertical shortening of the ITB could result in horizontal shortening of the lateral retinaculum. Wu and Shih used radiographs and CT scans to assess the influence of proximal ITB release on patellar tracking, and found a significant improvement in congruence and tilt angles, which was greater than that reported for lateral retinacular release.[44]

To date, no complications directly related to release of the ITB have been reported in the literature, making the procedure relatively safe.

\section{Conclusion}

Stress fractures of the patella are rare. The diagnosis is often missed, and radiographs may be normal. The risk of progression in undisplaced patellar stress fractures is high. A high index of suspicion and further investigation with MRI or bone scan is recommended in the athlete with anterior knee pain and localised patellar tenderness.

Non-operative management with immobilisation and observation is indicated for undisplaced fractures. Patients who require an immediate return to activity, or who have a displaced fracture, should be treated with open reduction and internal fixation. Return to sport can be expected between 6 and 12 weeks.

We recommend that ITB release should be considered as an adjunct at the time of fracture fixation. By reducing patellofemoral stress, this procedure may be of benefit in the management of patellar stress fracture.

\section{Consent}

Written informed consent was obtained from the patient for publication of this case report and accompanying images. A copy of the written consent is available for review by the Editor-in-Chief of this journal.

\section{Competing interests}

The authors declare that they have no competing interests.

\section{Authors' contributions}

AK was involved in analysis and interpretation of data, review of the literature and drafting and revision of the manuscript. PB was involved in study conception, interpretation of data, and revision of the manuscript. PC was involved in acquisition of data, and revision of the manuscript. RM was involved in study conception, acquisition and interpretation of data, and revision of the manuscript. All authors read and approved the final manuscript.

\section{References}

I. Brogle PJ, Eswar S, Denton JR: Propagation of a patellar stress fracture in a basketball player. Am J Orthop 1997, 26:782-784.

2. Crowther MA, Mandal A, Sarangi PP: Propagation of stress fracture of the patella. Br J Sports Med 2005, 39:e6.

3. Devas MB: Stress fractures of the patella. J Bone Joint Surg $\mathrm{Br}$ |960, 42-B:7|-74.

4. Dickason JM, Fox JM: Fracture of the patella due to overuse syndrome in a child. A case report. Am J Sports Med 1982, 1 0:248-249.

5. Garcia Mata S, Hidalgo Ovejero A, Martinez Grande M: Transverse stress fracture of the patella in a child. J Pediatr Orthop B 1999, 8:208-2 II.

6. Garcia Mata S, Martinez Grande M, Hidalgo Ovejero A: Transverse stress fracture of the patella: a case report. Clin J Sport Med 1996, 6:259-26I.

7. Iwaya T, Takatori $Y$ : Lateral longitudinal stress fracture of the patella: report of three cases. J Pediatr Orthop 1985, 5:73-75.

8. Jerosch JG, Castro WH, Jantea C: Stress fracture of the patella. Am J Sports Med 1989, I 7:579-580.

9. Orava S, Taimela S, Kvist M, Karpakka J, Hulkko A, Kujala U: Diagnosis and treatment of stress fracture of the patella in athletes. Knee Surg Sports Traumatol Arthrosc 1996, 4:206-2 I I.

10. Pietu G, Hauet P: Stress fracture of the patella. Acta Orthop Scand 1995, 66:48|-482.

II. Rockett JF, Freeman BL 3rd: Stress fracture of the patella. Confirmation by triple-phase bone imaging. Clin Nucl Med 1990 , I 5:873-875.

12. Schranz PJ: Stress fracture of the patella. Br J Sports Med 1988 , 22:169.

13. Teitz CC, Harrington RM: Patellar stress fracture. Am J Sports Med 1992, 20:761-765.

14. Bloomfield P, Watson A: A new clinical test: The iliotibial band/ lateral retinaculum (ITB/LR) test description and reliability study. New Zealand Journal of Sports Medicine 2000, 28:4-8.

15. McConnell J: The management of chondromalacia patellae: a long term solution. The Australian Journal of Physiotherapy 1986, 32:215-223. 
16. Muller W: Der militarische Abrissermudungsschaden. Deutsch Militararzt 1943, 8:283-286.

17. Kaye JJ, Freiberger RH: Fragmentation of the lower pole of the patella in spastic lower extremities. Radiology I97I, 10 I:97-I00.

18. Mann M: [Fatigue fractures of the lower patellar pole in adolescents with cerebral movement disorders]. Z Orthop Ihre Grenzgeb 1984, 122:167-170.

19. Rosenthal RK, Levine DB: Fragmentation of the distal pole of the patella in spastic cerebral palsy. J Bone Joint Surg Am 1977, 59:934-939.

20. Grace JN, Sim FH: Fracture of the patella after total knee arthroplasty. Clin Orthop Relat Res 1988:168-175.

21. McBryde AM Jr: Stress fractures in athletes. J Sports Med 1975, 3:212-217.

22. Hulkko A, Orava S: Stress fractures in athletes. Int I Sports Med 1987, 8:221-226.

23. Lombardo SJ, Benson DW: Stress fractures of the femur in runners. Am / Sports Med 1982, 10:219-227.

24. Matheson GO, Clement DB, McKenzie DC, Taunton JE, Lloyd-Smith DR, Maclntyre JG: Stress fractures in athletes. A study of $\mathbf{3 2 0}$ cases. Am J Sports Med 1987, 15:46-58.

25. Walter NE, Wolf MD: Stress fractures in young athletes. $A m$ Sports Med 1977, 5:165-170.

26. Stanitski $\mathrm{CL}, \mathrm{McM}$ aster JH, Scranton PE: On the nature of stress fractures. Am / Sports Med 1978, 6:391-396.

27. Norfray JF, Schlachter L, Kernahan WT Jr, Arenson DJ, Smith SD, Roth IE, Schlefman BS: Early confirmation of stress fractures in joggers. JAMA 1980, 243:1647-I649.

28. Terry GC, Hughston JC, Norwood LA: The anatomy of the iliopatellar band and iliotibial tract. Am J Sports Med 1986, 14:39-45.

29. Vieira EL, Vieira EA, da Silva RT, Berlfein PA, Abdalla RJ, Cohen M: An anatomic study of the iliotibial tract. Arthroscopy 2007, 23:269-274.

30. Perry J, Antonelli D, Ford W: Analysis of knee-joint forces during flexed-knee stance. J Bone Joint Surg Am 1975, 57:961-967.

31. Huberti HH, Hayes WC: Patellofemoral contact pressures. The influence of q-angle and tendofemoral contact. J Bone Joint Surg Am 1984, 66:715-724

32. Reilly DT, Martens M: Experimental analysis of the quadriceps muscle force and patello-femoral joint reaction force for various activities. Acta Orthop Scand 1972, 43:126-137.

33. Hayes WC, Snyder B: Toward a quantitative formulation of Wolff's law in trabecular bone. Am Soc Mech Eng Appl Mech Div 1981, 45:43-68.

34. Raux P, Townsend PR, Miegel R, Rose RM, Radin EL: Trabecular architecture of the human patella. J Biomech 1975, 8:1-7.

35. Hayes WC, Boyle D, Velez A: Functional adaptation in the trabecular architecture of the human patella. Trans Orthop Res Soc 1977, 2:1 I4.

36. Fulkerson JP, Hungerford DS: Disorders of the Patellofemoral Joint Second edition. Baltimore: Williams and Wilkins; 1990.

37. Bizzini M, Childs JD, Piva SR, Delitto A: Systematic review of the quality of randomized controlled trials for patellofemora pain syndrome. J Orthop Sports Phys Ther 2003, 33:4-20.

38. Puniello MS: Iliotibial band tightness and medial patellar glide in patients with patellofemoral dysfunction. J Orthop Sports Phys Ther 1993, 17:144-148.

39. Gerrard B: The patello-femoral pain syndrome: a clinical trial of the McConnell programme. The Australian Journal of Physiotherapy 1989, 35:71-80.

40. Winslow J, Yoder E: Patellofemoral pain in female ballet dancers: correlation with iliotibial band tightness and tibial external rotation. J Orthop Sports Phys Ther 1995, 22:18-21.

4I. Hudson Z, Darthuy E: Iliotibial band tightness and patellofemoral pain syndrome: a case-control study. Man Ther 2009 , 14:|47-I5I.

42. Doucette SA, Goble EM: The effect of exercise on patellar tracking in lateral patellar compression syndrome. Am J Sports Med 1992, 20:434-440.

43. Micheli LJ, Stanitski CL: Lateral patellar retinacular release. Am J Sports Med 1981, 9:330-336.

44. Wu CC, Shih $\mathrm{CH}$ : The influence of iliotibial tract on patellar tracking. Orthopedics 2004, 27:199-203.

45. Herrington L, Rivett N, Munro S: The relationship between patella position and length of the iliotibial band as assessed using Ober's test. Man Ther 2006, I I:182-I86.
46. Kwak SD, Ahmad CS, Gardner TR, Grelsamer RP, Henry JH, Blankevoort L, Ateshian GA, Mow VC: Hamstrings and iliotibial band forces affect knee kinematics and contact pattern. J Orthop Res 2000, 18: 10।-108.

47. Arno S: The a angle: a quantitative measurement of patella alignment and realignment. J Orthop Sports Phys Ther 1990, I 2:237-242.

48. Davies GJ, Wallace LA, Malone T: Mechanisms of selected knee injuries. Phys Ther 1980, 60:1590-1595.

49. Gose JC, Schweizer P: Iliotibial band tightness. J Orthop Sports Phys Ther 1989, 10:399-407.

50. Fulkerson JP: The etiology of patellofemoral pain in young, active patients: a prospective study. Clin Orthop Relat Res 1983:129-133.

5I. Insall J: Current Concepts Review: patellar pain. J Bone Joint Surg Am 1982, 64:147-152

52. Kramer PG: Patella malalignment syndrome: rationale to reduce excessive lateral pressure. J Orthop Sports Phys Ther 1986, 8:30I-309.

53. Paulos L, Rusche K, Johnson C, Noyes FR: Patellar malalignment: a treatment rationale. Phys Ther 1980, 60:1624-1632.

54. Yates CK, Grana WA: Patellofemoral pain in children. Clin Orthop Relat Res 1990:36-43.

55. Hungerford DS, Barry M: Biomechanics of the patellofemoral joint. Clin Orthop Relat Res 1979:9-I5.

56. Larson RL, Cabaud HE, Slocum DB, James SL, Keenan T, Hutchinson $\mathrm{T}$ : The patellar compression syndrome: surgical treatment by lateral retinacular release. Clin Orthop Relat Res 1978:I58-167.
Publish with Bio Med Central and every scientist can read your work free of charge

"BioMed Central will be the most significant development for disseminating the results of biomedical research in our lifetime. "

Sir Paul Nurse, Cancer Research UK

Your research papers will be:

- available free of charge to the entire biomedical community

- peer reviewed and published immediately upon acceptance

- cited in PubMed and archived on PubMed Central

- yours - you keep the copyright
BioMedcentral 